\title{
Research Paper: Dissociation of Inflectional and Derivational Morphology in Persian: Evidence From Aphasic Patients
}

\author{
Amer Gheitury ${ }^{1}$, Leila Dianat ${ }^{2 *}$, Shoja Tafakkori Rezaei ${ }^{3}$ \\ 1. Associate Professor, Department of English, Faculty of Literature, Razi University, Kermanshah, Iran. \\ 2. PhD, Department of English, Faculty of Literature, Razi University, Kermanshah, Iran. \\ 3. Assistant Professor, Department of English, Faculty of Literature, Razi University, Kermanshah, Iran.
}

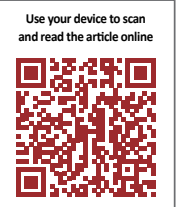

Citation: Gheitury A, Dianat L, Tafakkori Rezaei Sh. Dissociation of Inflectional and Derivational Morphology in Persian: Evidence From Aphasic Patients. Journal of Modern Rehabilitation. 2017; 11(1):37-44. https://doi.org/10.18869/nirp.jmr.11.1.37

: https://doi.org/10.18869/nirp.jmr.11.1.37

Article info:

Received: 25 May 2016

Accepted: 01 Oct. 2016

\section{Keywords:}

Dissociation, Inflectional and derivational morphology, Broca's aphasia, Generative linguistics

\section{ABSTRACT}

Introduction: It is believed that different components of our linguistic capabilities are not impaired to the same extent in aphasic patients. Moreover theoretical issues on aphasia can be researched on patients with different languages. Thus, we aimed to study the dissociation of inflectional and derivational morphology by assessing the performance of 8 Persian bilingual aphasic patients in producing Persian derivational and inflectional words.

Materials and Methods: To explore the capability of patients in using derivational and inflectional words, in addition to obtaining a brief history from all patients and an image of the impaired regions of the brain, two types of tasks, word-repetition and spontaneous speech tasks, were administered to them. The results were then statistically analyzed to see which part of their word-formation competence, derivational or inflectional processes, was impaired more seriously.

Results: The results of word-repetition and spontaneous speech tests indicated that patients did better at derivational morphology. In addition, a quantitative analysis revealed a gap between scores for derivational and inflectional words, confirming the dissociation of the two types of the process as claimed by generative linguists.

Conclusion: Based on the results patients had a better performance on derivational words as compared to inflectional ones confirming this linguistic theory that the two types of process take place in different sections, i.e. derivational process belongs to morphology whereas inflectional process is basically syntactic.

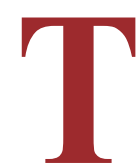

\section{Introduction}

he idea that derivational and inflectional processes are not impaired to the same extent, besides evidence available from aphasia studies, are equally motivated by a theoretical debate within generative linguistics on the modular nature of the language knowledge and the place of word-formation

* Corresponding Author:

Leila Dianat, PhD

Address: Department of English, Faculty of Literature, Razi University, Kermanshah, Iran.

Tel: +98 (933) 1468533

E-mail: 1553.dianat@gmail.com 
processes within linguistic theory. As one of the earliest accounts of morphology, Chomsky in "Aspects" argued for separation of the lexicon from the rewrite rules because part of the information for a lexical entry is idiosyncratic which should be included in the lexicon not in the general rewrite rules [1].

Here as Carstairs-MaCarthy noted, one finds "the first outline of a generative theory of the lexicon, with proposals on how lexical entries are structured and organized" [2]. In "Aspects", nouns such as destruction, refusal, and sincerity, much like gerundive nominals, are claimed to be entirely productive and derived by nominalization transformations from destruct, refuse, and sincere. Chomsky explicitly dismisses the idea that words such as destruction, refusal and sincerity enter the lexicon as such; instead, the lexical entries for the verbs destroy and refuse and the adjective sincere will contain information about the phonological shape they assume while undergoing nominalization [3].

Some years later, however, Chomsky changed his idea and abandon the transformational account that linked a derived noun like destruction and the verb destruct. Reviewing some English gerundive and derived nominalizations, he observed "many striking differences between these two nominalizations such as productivity of the process, the general relation between the nominal and the associated proposition, and the internal structure of the nominal phrase." Gerundive nominal can be developed freely from the propositions of subjectpredicate form, and the relation of meaning between the nominal and the proposition is quite straight. In addition, the nominal lacks the internal structure of a noun phrase and the semantic interpretation of a gerundive nominal is straightforward. In derived nominals, productivity is more restricted and the semantic relations between the associated proposition and the derived nominal are quite idiosyncratic, also the internal structure likens a noun phrase [3].

As a result, all derived nominals, as Chomsky explained, are formed by lexical rules in the lexicon. Such an idea which was a step toward diminishing the scope of transformations became known as the lexicalist position as against the transformational account adopted by followers of generative semantics aimed to explain all nominalizations via transformations. The outcome for morphology was a richer lexicon where all derivational processes took place. The idea was in later years contested by linguists who adopted a strong lexicalist position arguing for an even richer lexicon where both types of process were located.
The dissociation of inflectional and derivational processes and the performance of aphasic patients in using these processes has been an interesting area of research in language disorders. Miceli and Caramazza in 1988 reported results of a research on an Italian aphasic patient diagnosed with Broca aphasia who had difficulty in producing verbs, plural nouns, plural adjectives, and feminine adjectives. On this account, they also concluded that inflectional morphology is impaired more seriously than derivational morphology in patients with Broca aphasia [4].

In 2007, Hamilton and Branch Coslett reported a similar result by studying a patient with acquired phonological dyslexia who showed great difficulty in reading morphologically complex words, particularly inflected forms as compared with derived words. As they observed, "derived words are not processed via the same mechanisms as regularly inflected words." In other words, inflected words are processed via morphological decomposition, whereas derived words are presented in "whole-word form" [5].

Although in later morphological work in generative theory, i.e. the Strong Lexicalist Position, both processes are argued to take place in the lexicon, the dissociation of inflectional and derivational word-formation processes has continued to be a controversial and researchable topic. Researching Broca aphasia among speakers of languages other than English might be considered as another step toward both assessing theoretical concepts in the light of new data and a better recognition of factors bringing about language loss. Hence, to address these concerns, in this study we evaluated the dissociation of inflectional and derivational morphology in Iranian patients with Broca aphasia.

\section{Materials and Methods}

Four female and 4 male patients participated in the study aged 27-91 years, who were diagnosed with Broca aphasia due to stroke, head injury, or cerebral hemorrhage according to their medical reports. They were monolingual (Persian), bilingual (Persian-Lari/Lori) and trilingual (Persian-Turkish-Lari) speakers. Given patients' speech characteristics and mental conditions, the tests and interviews were conducted with much patience and in several sessions after obtaining their consent. During test sessions, patients' physical and mental conditions were taken into account so as not to make them weary or put them under pressure. The tests were administered in several sessions. 
Case 1

M. M. is a 65 years old female, right-handed and bilingual speaker of Persian-Lari. She is a retired employee with associated degree. In January 2015, she suffered a trauma in the left hemisphere involving the frontoparietal lobe leaving her with right hemiplegia and weakness.

Case 2

R. K. is a 86 years old female, right-handed. She is a housewife with a diploma degree and bilingual speaker of Persian-Lari. She suffered from ischemic CVA in February 2015. Her CT scan showed diffuse brain parenchymal atrophy in the left hemisphere involving left frontal lobe that left her a right hemiplegia.

\section{Case 3}

A. A. is a 50 years old male, right-handed and multilingual speaker of Persian, Turkish and Lari. He is an employee with BA degree. In August 2015, he suffered a CVA due to cerebral vascular thrombosis in the frontal lobe of the right hemisphere leaving him with muscle weakness.

\section{Case 4}

M. S. is a 81 years old female, right-handed and bilingual speaker of Persian-Lari. She is a housewife with 6 years of education. In March 2015, his CT scan revealed intracerebral hemorrhage due to head trauma in the frontal lobe of the left hemisphere leaving her with a right hemiplegia.

\section{Case 5}

Gh. A. is a 91 years old male, right-handed, native speaker of Persian with 2 years of education. His CT scan revealed an ischemic CVA with a bilateral diffuse brain parenchymal atrophy and moderate cerebral ventricular dilatation in the left hemisphere involving the frontal lobe in April 2015 that affected him with a severe weakness.

\section{Case 6}

J. J. is a 70 years old female, right-handed, native speaker of Persian. She is housewife and illiterate. In May 2015, she suffered from intracerebral hemorrhage due to warfarin abuse in the frontal lobe of right hemisphere leaving her with left hemiplegia and weakness.

\section{Case 7}

A. T. is a 72 years old male, right-handed, bilingual speaker of Persian-Lori. He is a retired employee with BA degree. In May 2015, his CT scans revealed ischemic CVA with diffuse brain parenchymal atrophy as well as severe cerebral ventricular dilatation in the left hemisphere affecting the frontal lobe, leaving him with right hemiplegia and weakness.

\section{Case 8}

M. K. is a 27 years old male, right-handed, native speaker of Persian. He is an employee with BA degree. He suffered from ischemic CVA due to congenital anomaly in the frontal lobe of right hemisphere in February 2016 that left him with left hemiplegia and weakness.

Table 1. The characteristics of eight aphasic patients

\begin{tabular}{|c|c|c|c|c|c|c|c|c|}
\hline Patient & M. M. & R. K. & A. A. & M. S. & Gh. A. & J. J. & A. $\mathrm{T}$. & M. K. \\
\hline Age, $y$ & 65 & 86 & 50 & 81 & 91 & 70 & 72 & 27 \\
\hline Gender & Female & Female & Male & Female & Male & Female & Male & Male \\
\hline Language & Persian, Lari & $\begin{array}{l}\text { Persian, } \\
\text { Lari }\end{array}$ & $\begin{array}{l}\text { Persian, Lari, } \\
\text { Turkish }\end{array}$ & $\begin{array}{c}\text { Persian, } \\
\text { Lari }\end{array}$ & Persian & Persian & $\begin{array}{l}\text { Persian, } \\
\text { Lari }\end{array}$ & Persian \\
\hline Handedness & Right & Right & Right & Right & Right & Right & Right & Right \\
\hline Education & $\begin{array}{l}\text { Associate } \\
\text { degree }\end{array}$ & Diploma & BA & $\begin{array}{c}\text { Elementary } \\
\text { school }\end{array}$ & $\begin{array}{c}\text { Elementary } \\
\text { school }\end{array}$ & Illiterate & BA & $\mathrm{BA}$ \\
\hline Broca etiology & Trauma & CVA & CVA & Trauma & CVA & $\mathrm{ICH}$ & CVA & CVA \\
\hline Lesion side & Left & Left & Right & Left & Left & Right & Right & Right \\
\hline Oneset & $\begin{array}{c}\text { January } \\
2015\end{array}$ & $\begin{array}{c}\text { February } \\
2015\end{array}$ & August 2015 & $\begin{array}{c}\text { March } \\
2015\end{array}$ & $\begin{array}{l}\text { April } \\
2015\end{array}$ & $\begin{array}{l}\text { May } \\
2015\end{array}$ & $\begin{array}{l}\text { May } \\
2015\end{array}$ & $\begin{array}{c}\text { February } \\
2016\end{array}$ \\
\hline
\end{tabular}


It should be noted that patients were diagnosed with mild Broca aphasia based on Bilingual Aphasia Test (BAT, Farsi version). All patients (except Gh. A.) have regularly participated in physiotherapy program and all (except M. S., Gh. A. and J. J.) attended speech therapy program from the time the impairment was diagnosed. Table 1 summarizes the details of all patients. Moreover, the patients' damaged brain regions were identified by means of CT scan images which showed the patients' brain from different angles. To confirm the brain damage, the CT scan was performed for all the patients in Lar and Jahrom hospitals and rehabilitation center.

Tests

\section{Word repetition test}

Persian morphology uses a number of suffixes and prefixes to form derivational words of different parts of speech. As we see in the following examples, the suffixes -mand, -gar, $-i,-b \bar{a} n$, -gin, and the prefixes ham-, $n \bar{a}-$ are used to form derived nouns and adjectives.

Sud+-mand: 'use+ful'(derived adjective)

Kār+-gar: 'work+er'(derived noun)

Gel+-i : 'mud $+d y$ ' (derived adjective)

Bāgh+-bān: 'garden+er'(derived noun)

Sharm+-gin: 'embarrassed'(derived adjective)

Ham-+kelās: 'classmate'(derived noun)

Nā-+shakibā: 'impatient'(derived adjective)

Inflectional morphemes such as the plural marker -hā/ $\bar{a} n$, the comparative marker -tar, and the superlative marker -tarin, as we see in the following examples, are attached after all derivational processes have taken place.

Gol+-ha: 'flowers'

Sard+-tar: 'colder'

Sard+-tarin: 'coldest'

In addition, the Persian verb, as examples below indicate, is often inflected for tense, aspect, mood, and agreement.

$$
\begin{aligned}
& \text { Raft+-am: 'went-I' } \\
& \text { Raft+-im: 'went-we' }
\end{aligned}
$$

Each patient was asked to repeat 200 high frequency Persian words during test sessions while their repetitions were recorded. The words were 100 inflectional and 100 derivative ones selected from several Persian grammar books which were also frequently used in daily conversations. The inflectional and derivational words belonged to four parts of speech, that is, 60 nouns, 40 verbs, 70 adjectives, and 30 adverbs. The reason for asking patients to repeat the words rather than naming pictures is the fact that naming pictures for patients diagnosed with Broca aphasia was time-consuming let alone the patients might not even find the word the researcher meant to ask. For example, patients might name the image of flowers gol, 'flower' instead of gol-ha 'flowers' without distinguishing between singular and plural form of the noun. Also finding a picture that could represent gol-i 'a flower' was impossible.

\section{Spontaneous speech test}

Spontaneous speech is one of the methods employed to evaluate aphasic patients' speech because they may have difficulty repeating or producing a certain word while at the same time be able to utter the same word impromptu. In this test, patients were asked to explain about their everyday issues and daily chores such as cooking, housecleaning, the place of residence, number of their children within 5 to 10 minutes. This test was administered aiming to investigate the number of inflectional and derivational words patients produced.

\section{Statistical analysis}

The data were entered in SPSS version 22. To determine the normal distribution of data, KolmogorovSmirnov test was used. Independent student $t$ test was used to compare the error rate between inflectional and derivational processes on word repetition test. $\mathrm{P}$ value less than 0.05 was considered significant.

\section{Results}

\section{Results of word repetition test}

Table 2 shows the number of patients' errors on each category. It includes information such as patients' name abbreviation, inflectional and derivative category of words as well as the total errors of each patient in the production of the two types of process. The total inflectional errors of all patients were 452 out of 800 and the total derivational errors of all patients were 407 out of 800. Comparing the sum of inflectional and derivational errors of each patient indicates that patients were worse 
Table 2. Patients' errors based on functional category of the words used in the repetition test

\begin{tabular}{|c|c|c|c|c|c|c|c|c|c|}
\hline Patients & & M. M. & R. $K$. & A. A. & M. S. & Gh. A. & J. J. & A. $\mathrm{T}$. & M. K. \\
\hline \multirow{5}{*}{$\begin{array}{l}\text { Inflectional } \\
\text { process }\end{array}$} & N+/-hā/, /-ān/ & 15 & 16 & 14 & 18 & 17 & 17 & 13 & 14 \\
\hline & $\mathrm{N}, \mathrm{Adv}+/-\mathrm{i} /$ & 7 & 9 & 8 & 9 & 10 & 7 & 8 & 6 \\
\hline & (Prefix) $+V+($ Suffix $)$ & 19 & 23 & 20 & 23 & 24 & 22 & 20 & 23 \\
\hline & Adj+ /-tar/, /tarin/ & 5 & 7 & 6 & 8 & 9 & 7 & 6 & 6 \\
\hline & Adv+ /-hā/, /-ān/ & 4 & 5 & 3 & 3 & 4 & 5 & 6 & 6 \\
\hline \multirow[t]{7}{*}{$\begin{array}{l}\text { Total inflectional } \\
\text { errors }\end{array}$} & & 50 & 60 & 51 & 61 & 64 & 58 & 53 & 55 \\
\hline & N, V+/-eš/ & 6 & 5 & 4 & 4 & 3 & 6 & 5 & 5 \\
\hline & $\mathrm{N}, \mathrm{V}, \mathrm{Adj}+/-\mathrm{h} /$ & 4 & 4 & 3 & 3 & 2 & 3 & 3 & 4 \\
\hline & $\operatorname{Adj}+/-i /$ & 5 & 6 & 4 & 5 & 4 & 4 & 4 & 5 \\
\hline & V+/-ār/ & 2 & 2 & 1 & 2 & 2 & 3 & 2 & 2 \\
\hline & N+/-gar/, /-bān/, /-če/, /-dān/ & 2 & 3 & 4 & 3 & 4 & 3 & 3 & 3 \\
\hline & $\mathrm{N}, \mathrm{V}, \mathrm{Adj}+/-\mathrm{h} /$ & 2 & 1 & 2 & 1 & 2 & 1 & 2 & 1 \\
\hline \multirow[t]{7}{*}{$\begin{array}{l}\text { Derivational } \\
\text { process }\end{array}$} & $\mathrm{N}$, Pronoun+/-i/ & 6 & 6 & 5 & 7 & 7 & 5 & 7 & 7 \\
\hline & $\mathrm{N}+/$-mand/ & 2 & 2 & 1 & 2 & 2 & 1 & 2 & 2 \\
\hline & V+/-ā/, /v-ān/,/-ande/ & 3 & 3 & 4 & 4 & 4 & 6 & 4 & 3 \\
\hline & Adj+/-gin/, /-nāk/ & 1 & 4 & 2 & 3 & 2 & 3 & 3 & 3 \\
\hline & /nā-/,/-bā/+Adj, N, V & 6 & 8 & 8 & 7 & 9 & 8 & 6 & 8 \\
\hline & $/ \mathrm{bi}-/+\mathrm{N}$ & 5 & 6 & 6 & 8 & 6 & 5 & 7 & 5 \\
\hline & N, Adj+/-āne/ & 3 & 5 & 4 & 4 & 3 & 4 & 3 & 3 \\
\hline $\begin{array}{l}\text { Total derivational } \\
\text { errors }\end{array}$ & & 47 & 55 & 48 & 53 & 50 & 52 & 51 & 51 \\
\hline
\end{tabular}

at inflectional words as compared to derivational ones. Likewise, verbs were the category with worst impairment plausibly due to their complex inflectional nature indicating a number of features such as tense, aspect, mood, and agreement. As far as verbs are concerned, results confirm De Bleser and Kauschke [6] observation that in aphasic patients the verb, due to its complex structure and meaning, is the most seriously impaired category.
To determine the normal distribution of data, Kolmogorov Smirnov test, a nonparametric test, was used. Based on this test, the distribution of data was normal $(\mathrm{P}>0.05)$. Then a t test was used to assess the error rate for inflectional and derivational processes on word repetition test, which indicated a significant difference between the sum of errors for the two types of process $(\mathrm{P}>0.05)$ ( Table 2, Figure 1). 


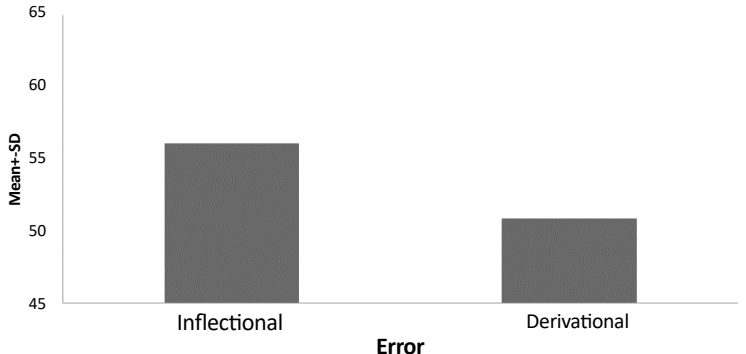

$J \mathrm{MR}$

Figure 1. Error rate of inflectional and derivational words produced in word repetition

\section{The result of spontaneous speech test}

In spontaneous speech test, the total inflectional words of all patients were 32 out of 211 and the total derivational words of all patients were 56 out of 211 (Table 3, Figure 2).

\section{Discussion}

This study aimed to explore the performance of 8 Persian speaking patients with Broca's Aphasia in using inflectional and derivational words. The results of word repetition and spontaneous speech tests indicated a significantly better performance on derivational words compared to inflectional ones. Although the claim that the two processes are not impaired to the same extent in patients with Broca's Aphasia is borne out by the results of the present study, the place in the linguistic theory where each process takes place remains controversial. This can be clearly observed in the various generative accounts of the lexicon and morphological issues following Chomsky [3] and then Halle [7].

Following Chomsky's [1] opinion that semantically irregular derivations should not be represented by syntax, two opposing positions developed. The Strong Lexicalist Hypothesis took Chomsky's idea to its extreme boundaries, excluding all word formation topics from syntax. Then, all processes of word formation including the inflection rules were claimed to be applied in the Lexicon. This position was originally proposed in Halle's [7] in-

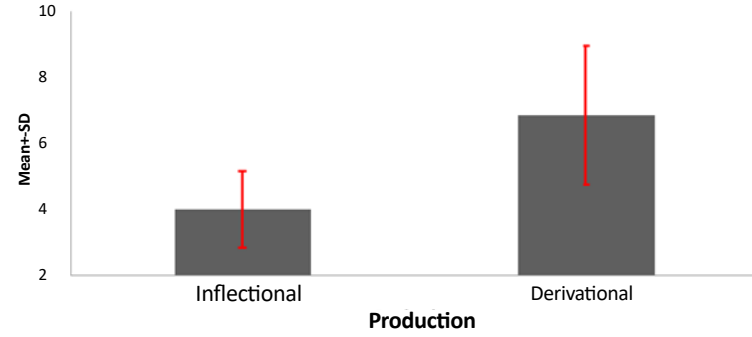

JMR

Figure 2. Inflectional and derivational words produced in spontaneous speech

novative paper on generative morphology and has been widely accepted as part of the most influential theories of syntax, including Lexical Functional Grammar, Generalized Phrase Structure Grammar, Head Driven Phrase Structure Grammar, and Minimalist Program. The Strong Lexicalist Hypothesis is usually augmented by the assumption that syntactic rules cannot modify, move or delete parts of words, known as Principle of Lexical Integrity, which has been adopted by many morphologists [8-10]. The principle was also defined as Generalized Lexicalist Hypothesis [8] which allows no syntactic rule to refer to elements of morphological structure. The Strong Lexicalist Hypothesis demands a clear cut division between syntax and morphology and, as such, it fails to explain a variety of phenomena that require some degree of interaction of these two components of the theory.

Most morphologists working within the lexicalist framework presume that derivation and inflection are different morphological processes. In particular, Anderson in 1982 defined inflection as the morphology that "is relevant to the syntax." Thus, he realized all the morphosyntactic features of a word (Plural, Indicative, Active, etc.) depending on the syntactic context in which the word is inserted. Inflection plays, therefore, the role of "adjusting" the words provided by the lexicon to the morphosyntactic requirements of the syntax [11]. Other linguists assume that inflection and derivation are instances of affixation, and their differences can be explained as a matter of ordering. This approach is supported in Kiparsky's model of Lexical Morphology. He

Table 3. The number words produced in spontaneous speech test

\begin{tabular}{ccccccccc}
\hline Patient & M. M. & R. K. & A. A. & M. S. & Gh. A. & J. J. & A. T. & M. K. \\
\hline All words & 26 & 23 & 36 & 20 & 16 & 28 & 32 & 30 \\
Derivational words & 7 & 5 & 10 & 5 & 4 & 8 & 9 & 8 \\
\hline Inflectional words & 3 & 3 & 6 & 4 & 1 & 4 & 6 & 5
\end{tabular}


assumes that both word-formation rules and phonological rules are applied in the lexicon in an orderly progression of cycle $[12,13]$.

In generative syntactic theories, the relevant morphosyntactic information is provided by or checked in functional categories in the syntactic tree. For example, a verb has to move to functional categories such as AGR and TENSE to collect or check inflectional features encoding information on tense and subject-verb agreement. Consistent with this syntactic view of inflection are deficit accounts. They attribute impairments with inflection to syntactic deficits. In such accounts, either the functional categories relevant for the realization of inflectional markers cannot be projected, resulting in pruned syntactic trees [14], or the morphosyntactic information hosted in specific functional nodes is left unspecified. A problem at the functional node TENSE will be responsible for a deficit that selectively affects tense inflection, but spares agreement inflection.

In more recent syntactic theories like the Minimalist Program, the lexicon projects fully inflected forms into syntax and the morphosyntactic properties of these lexical elements determine the formation of syntactic structure. In such theories, problems with inflection might not be related to functional categories, but might have already arisen in the lexicon where the inflected form is built. Under a lexicalist account, inflectional deficits might originate from difficulties in accessing inflected forms or affixes in the mental lexicon [15].

However, the dissociation of these processes does not mean the dissociation of syntax and morphology to Miceli and Caramazza [4]. Following a Strong Lexicalist Hypothesis particularly that of Lapointe [8], they reasoned that all morphological operations, both inflectional and derivational, are stationed in the lexicon. In their model [4], lexicon has three components: a set of root morphemes, a set of derivational affixes and rules of affixation (DPC), as well as a set of inflectional affixes with rules of affixation (IPC).

Base plus derivational and inflectional affixes interact with different kinds of information in the syntactic component and only the latter are sensitive to the morphosyntactic representation specified at the S-structure level. They stated their claim in terms of a sentence production model by Garrett [16]. He justified two separate stages in dealing with speech errors: meaning-related errors (word switches of content words with the same grammatical function) occur during the functional stage (FL), and form-related or functional errors (morpheme switches and errors of grammatical sounds) occur during the positional stage of processing (PL). He also justified the positional stage as being independent of the functional stage because of phonological accommodation [16].

Despite what outlined above, it seems that in future research studies, dissociation is no longer the main issue compared to the theoretical outcome with which to argue for the lexical or syntactic nature of derivational and inflectional processes within the theory. Though the clinical evidence available from research on aphasia and other communication disorders bring forth strong evidence in support of dissociation of the two morphological processes, the results of these studies might be used to whatever explanations in the generative literature, that is, a strong lexicalist, weak lexicalist, or a syntax-based explanation. However, the issue can also be considered in relation to parallel studies in deafness studies where the evidence indicates serious impairment of inflectional morphology as against derivational processes in individuals with little or no early language experience.

A case study by Gheitury et al. (2012) evaluated the written performance of a young deaf woman and reported serious problems with syntax and inflectional morphology, which occurred frequently throughout the texts she wrote. Derivational morphology was, nevertheless, affected much less than the inflectional morphology, only $4 \%$ compared to $28 \%$ [17].

This study has some limitations and lack of the relevant sample was the most serious limitation as all previous studies reviewing in this paper were case reports. Our experience was a case series and we reported the results of 8 patients; however, because of small sample size we cannot generalize the findings reported here.

In this study, we showed that the results of word repetition and spontaneous speech tests indicated a better performance on derivational words as compared to inflectional ones. It seems that evidence obtained so far speaks in favor of a dissociation of the two categories. However, the controversy on the location of derivational and inflectional processes within linguistic theory is in need of future research on language impairments and other domains in communication disorders such as deafness, which will deal with morphological issues as such.

\section{Acknowledgments}

We would like to thank the patients for their contribution to this study without which this project would have been impossible. The present paper was extracted from the 
second author's PhD thesis in the Department of English, Faculty of Literature, Razi University, Kermanshah, Iran.

\section{Conflict of Interest}

The authors declared no conflicts of interest.
[16] Garret, M. Level of processing in sentence production. In Butterworth B, editor. Language production. New York: Academic Press; 1980.

[17] Gheitury A, Sahraee AH, Hoseini M. Language acquisition in late critical period: A case report. Deafness \& Education International. 2012; 14(3):122-35. doi: 10.1179/1557069x12y.0000000008

\section{References}

[1] Chomsky N. Aspects of the theory of syntax. Cambridge: MIT Press; 1965.

[2] Carstairs McCarthy A. Current morphology. Didcot: Taylor \& Francis; 1992.

[3] Chomsky, N. Remarks on nominalization. In: Jacobs RA, Rosenbaum PS, editors. Reading in English Transformational Grammar. Cambridge: Ginn and Company; 1970.

[4] Miceli, G. (1988). Dissociation of inflectional and derivational morphology. Brain and Language. 35(1):24-65. doi: $10.1016 / 0093-934 \times(88) 90100-9$

[5] Hamilton AC, Coslett HB. Impairment in writing, but not reading, morphologically complex words. Neuropsychologia. 2007; 45(7):1586-90. doi: 10.1016/j.neuropsychologia.2006.12.003

[6] De Bleser R, Kauschke C. Acquisition and loss of nouns and verbs: Parallel or divergent patterns. Journal of Neurolinguistics. 2003; 16(2003): 213-29. doi: 10.1016/s0911-6044(03)000162

[7] Halle M. Prolegomena to a theory of word formation. Linguistic Inquiry. 1973; 4(1):3-16.

[8] Lapointe SG. A theory of grammatical agreement. Spokane: Garland Pub; 1980.

[9] Selkirk EO. The syntax of words. Cambridge: MIT Press;1982.

[10] Di Sciullo AM, Williams E. On the definition of word. Cambridge: MIT Press; 1987.

[11] Anderson SR. Where's morphology. Linguistic Inquiry. 1982; 13(4):571-612.

[12] Kiparsky P. From cyclic phonology to lexical phonology. In: van der Hulst $\mathrm{H}$, Smith $\mathrm{N}$, editors. The structure of phonological representations (I). Berlin: Walter de Gruyter; 1982.

[13] Kiparsky P. Word formation and the lexicon. Massachusetts: MIT Press; 1983.

[14] Friedmann N, Grodzinsky Y. Tense and agreement in agrammatic production: Pruning the syntactic tree. Brain and Language. 1997; 56(3):397-425. doi: 10.1006/brln.1997.1795

[15] Penke M. Morphology \& language disorder. In Ball MJ, Perkins MR, Muller N, Howard S, editors. The handbook of clinical linguistics. New Jersey: Blackwell Publication; 2008. 